\title{
De-stigmatising manipulation: An exercise in second-order empathic understanding
}

\author{
G Stanghellini, ${ }^{1,2}$ MD, Dr Phil h c \\ ${ }^{1} G$ d'Annunzio University, Chieti, Italy \\ ${ }^{2} D$ Portales University, Santiago, Chile
}

Corresponding author: G Stanghellini (giostan@libero.it)

\begin{abstract}
Standard definitions of 'manipulation', especially regarding people with a borderline personality diagnosis, usually highlight the alloplastic purpose of manipulativity, i.e. the intention to produce a belief in, or action by another person. In this article, I will try to show that this is only one side of the coin, and shed light on a complementary aspect of manipulative behaviour: manipulation can serve an epistemic, rather than alloplastic, pragmatic motif - the attempt to establish contact with the other in order to achieve a more distinct experience and representation of the other. My tentative hypothesis is based on the meaning of manipulation as touching ('manus' means 'hand') in infant behaviour where manipulation is a means to explore, rather than a way to modify the other's state of mind.
\end{abstract}

S Afr J Psych 2014;20(1):11-14. DOI:10.7196/SAJP.510

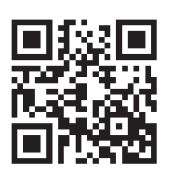

A vast range of behaviours are labelled with the term 'manipulation', both in clinical and non-clinical situations. This word is used to stigmatise morally wrong ways of interacting, lumping together bullying, intimidation, physical violence, building special relationships, corruption, creating divisions, conning and lying, deceiving and threatening. ${ }^{[1,2]}$ Manipulativity, although not an official diagnostic criterion for borderline personality disorder, is often used by clinicians to deplore the way in which these persons interact with others. Manipulation in people with borderline personality disorder is deemed deliberate and morally blameworthy rather than ill. Also, it is considered maladaptive since it reduces the other person's empathy towards the manipulator, undermining his/her desperate search for relationship and attention. Thus, manipulation is a term that tends to be over-inclusive and is affected by conceptual cloudiness and conflating moral values with clinical judgement.

Potter (p. 109) proposes a working definition of 'manipulativity' that can be summed up as follows: $:^{[1]}$ it is a behaviour that dramatises the manipulator's needs/emotions in ways designed to target a perceived vulnerability in the other, in order to effect desirable responses by the other in an indirect way, although the other feels/thinks that the manipulator is overdoing his/her own need/emotion, s/he (the other) feels trapped by them.

This definition highlights the alloplastic purpose of manipulativity: producing a belief in, or action by the other.

In this article, I attempt to show that this is only one side of the coin, and shed light on a complementary aspect of manipulative behaviour: manipulation can serve an epistemic, rather than alloplastic, pragmatic motif - the attempt to establish contact with the other in order to achieve a more distinct experience and representation of the other.

\section{An antipathetic behaviour}

Imagine the following situation: a woman in her forties, hospitalised in a surgery ward of a general hospital, behaves restlessly, and is impatient, irritating and complaining. She attacked a nurse with no apparent reason when she tried to give her medication, refuses drugs, makes a fuss, asks for special treatment, etc. Nurses say that the patient is over-demanding, continuously looks for attention, and tries to manipulate them. Some qualify her behaviours as 'acting out', saying that she behaves thoughtlessly and impulsively.

You, as a psychiatrist, are asked to interview the patient. During the interview you exclude all sorts of disorders of consciousness (e.g. lowered, clouded, narrowed or expanded consciousness) and orientation (in time, place, situation, etc.), as well as psychotic phenomena (e.g. delusions, hallucinations). Feeling more at ease, at a given point the patient tries to clarify: 'Nobody wanted to explain to me what was going on. I could not understand what they were doing to me. Everything so obscure. I felt nervous, worried about that. I just wanted to know. Do I have the right to know and to decide? Or should I go away?

During the staff meeting that follows your interview with the patient, you try to shed light on the motivations of the patient's behaviour, and on the staff's interpretations thereof. What is the purpose of this behaviour, if any? What is it about?

The first reaction is deeming her behaviour 'irrational', 'illogical', and 'unmotivated', thus 'incomprehensible' and 'almost crazy'. The majority, after a further reflection, suppose that her intention is 'manipulating,' 'controlling, 'manoeuvring' the others. Someone more softly assumes that she tries to 'persuade' the nurses to act the way she wants. As to her innermost reasons to behave like that, some conjecture that it is because of her 'need to dominate' the others. A doctor speaks of 'sadism' - she needs to get pleasure from harming 
the other. Someone speculates that she may be driven by her 'fear of the other' and her 'need to control' the other who is supposed to be harmful. 'Egoism' is another nurse's explanation for the patient's comportment - she has no concern for the other. 'Pure meanness', no respect for the other, is another interpretation.

In order to answer the question about the motivation or purpose of the patient's behaviour - you explain - we need to tackle another one: What kind of experience underpins this behaviour? Does the patient experience that given situation - being hospitalised in a surgery ward - as we do, or as we could expect ourselves, or 'everyman' to do?

\section{The life-world of manipulation}

Reflecting upon these issues produces more questions: Is this behaviour embedded in a life-world like our own? Does the patient's life-world - the reality she lives in, her experience of the surrounding world - bear some analogy with the life-world we live in? Or is it, totally or in part, different from our own life-world? And in the case that this behaviour was the expression of a different life-world, of a kind of world in its own right but unlike our own, what can we do to approximate the world the patient lives in?

Let's start with the first question. It seems self-evident, as it is implied by the 'shock experience' kindled by the patient's behaviour, that her conduct must be situated in a life-world that does not (at least, in part) overlap with our own.

If so, in what sort of life-world is this behaviour embedded? Before answering this question, we need to clarify a preliminary issue: what do we mean with 'life-world' and why is that concept relevant for us? This is the definition of 'life-world' by Schutz and Luckmann: ${ }^{[3}$ 'The reality which seems self-evident to men remaining within the natural attitude. This reality is the everyday life-world. The region of reality in which man can engage himself and which can change while he operates in it by means of his animate organism' (emphasis added).

The life-world is what each of us takes for granted to be the objective reality and meaning of the surrounding world - at least unless we reflect upon the way in which we contribute to establish this 'objectivity' and meaning. Although the majority of people belonging to a given culture are situated in a shared life-world, there are several other private life-worlds that are different from the 'everyday' lifeworld; e.g. fantasy worlds, the dream world, and what we may call psychopathological worlds.

Schutz and Luckmann ${ }^{[3]}$ further explain that each life-world is characterised by a given 'pragmatic motive', by a 'meaning-structure' and a 'style of subjective experience. The pragmatic motive is the implicit or unconscious reason/drive that motivates us to experience the world and to construe its meanings in that given way. As a consequence of this, the 'objects' and 'events' that a person finds in his/her life-world are structured according to a given style of experience that limits his/her potential for free action. Thus, the lifeworld is a province of practice of which the structure of meaning is deeply intertwined with one's necessity for action.

Our previous question, then, can be rephrased as follows: In what sort of 'province of meaning' and 'style of subjective experience' is our patient's behaviour embedded? If we are able to answer this preliminary question, then we will be able to render her behaviour meaningful and understandable.

Since the patient's behaviour is patently an 'antipathetic' one (as we can see from the staff's emotional reactions, comments and interpretations), in order to rescue its meaning, we cannot confine ourselves to standard empathic understanding. ${ }^{[4]}$ We cannot simply rely on our spontaneous capacity to put ourselves in her shoes, since the effect of her behaviour on ourselves is rather one of rejection. It seems rather impossible to empathise with this behaviour, at least in the standard meaning of this term; although the patient herself said, 'Nobody wanted to explain to me what was going on. I could not understand what they were doing to me', and that is a key to comprehend her behaviour (and thus to empathise with her). It will nonetheless remain difficult to empathise with her inability to grasp and make sense of what was happening to her. What exactly does she mean by, 'I could not understand what they were doing to me?', and why did she have that kind of experience? It seems clear that her 'experience' of the situation was quite different from the staff's understanding thereof. Instead, we need to seek another kind of understanding. We need to rescue the implicit structures of her lifeworld in order to make her behaviour understandable. Then, we can also try to empathise with it - or, at least, not to blame her for it.

\section{What is manipulation?}

As we have seen during the staff meeting, many agreed that the patient's behaviour was 'manipulative'. Manipulation is usually understood as an alloplastic behaviour, the attempt to modify external reality of an antipathetic kind. As such, usually manipulative people are blamed for that. A negative feeling (antipathy) and a negative-value judgement (blame) stand in the way and threaten attunement and understanding.

The interpretation changes, however, if manipulation in this person is understood as explorative behaviour, rather than as alloplastic. 'Manus' means 'hand'. Manipulation is a kind of touching. This is the metaphorical, and at the same time concrete domain of the stigmatised behaviour called 'manipulation'. Touch is the primordial source of knowledge and acquaintance - contact. Through touch, we explore, inspect, scout, check, examine and scrutinise the world around us, including other people. Doubtlessly, this is childish behaviour in the sense that it is proper to children before they develop other ways to get to know and evaluate reality. Nonetheless, nobody would deem manipulation in a child as comportment that should be blamed or discouraged, since one knows that this behaviour has a specific pragmatic motive and meaning in that province of reality and of meaning that we call 'childhood'. Children live in a world unlike our own; their practical possibilities for action are different from our own. Time, space and meanings are structured in a way dissimilar if compared to our own, as everybody knows - and as masterfully described in the novel The Child in Time by Ian McEwan. ${ }^{[5]}$ When we see a child manipulating something, we usually experience a feeling of sympathy and tenderness.

So what are the implications if our patient manipulates to get to know the other; and to make sense of the situation she is in? The related question is: what sort of experience/image/representation of the other and of the situation does she have so that she needs to be manipulative? 
To be true, we need to revisit what she said about that, although it appeared quite obscure, before we make the hypothesis that the meaning of manipulation was not manoeuvring the others, but rather to establish some sort of contact with the others and explore their behaviour.

Now it is quite easy to see that manipulating for her is not just a strategy to control or persuade the others. It could well be a way to get in touch - although in a quite clumsy way for our standards. Handling, laying hands on someone, fingering, touching, contacting, feeling, stirring, tapping, caressing, soothing, pressuring, squeezing, scratching, stretching, hurting, irritating, scraping, etc., are all ways to get in touch, meet and link with other people - although some of them may be annoying, exasperating, frustrating and vexing if performed by an adult and not by a child (or an animal, e.g. a primate) as we could expect.

Seen from that angle, the manipulative behaviour of our patient stops being a nuisance that has no clinical relevance. Rather, it becomes the mirror of her life-world and a heuristic device to get to know in great detail the province of meaning that she inhabits. It becomes a phenomenon that speaks of her way of being in the world and paves the way to our understanding of her being situated - and not simply a behavioural symptom to be eliminated.

\section{The 'pragmatic motive' of manipulation}

My tentative hypothesis - based on the meaning of manipulation as touching and on child behaviour - is that manipulation with some patients may be more exploration, less modification, of the other. Of course, this is neither the only, nor the ubiquitous meaning of manipulation, since manipulation in 'healthy' - or indeed in some 'unhealthy' people - may very well be about modification. Although I have not the ambition to establish a 'diagnostic criterion', I suggest that this side of manipulative behaviour may be rather typical of people with borderline personality disorder.

Manipulation is often a kind of behaviour attributed to people with severe personality disorder, e.g. borderline personality disorder. Of course, it is not legitimate to make a diagnosis on the basis of one single feature, especially if it is a behavioural one. What is at issue is the style of subjective experience that subtends this behaviour. In our example, the patient says something relevant about this, namely that she was unaware of 'what was going on', that 'everything was so obscure' and that she felt 'nervous' and 'worried' about that. Al this is not enough to reconstruct her style of experience. In other contributions, ${ }^{[6,7]}$ we argued that the appearance of the other as a dim and fuzzy person or as a tenebrous and suspect one is a key feature of the life-world of persons affected by dysphoric mood. Although the term 'dysphoria', in the narrower sense of irritable mood, is often used to designate mood states in different psychopathological conditions (including several personality disorders, affective disorders, organic psychoses, delusional disorders and schizophrenias) - and not only in borderline personality disorder - the quality and the consequences of dysphoric mood in borderlines is rather common. ${ }^{[8]}$

Dysphoria manifests itself as a prolonged, unmotivated, indistinct, and quasi-ineffable constellation of feelings that convey a nebula of vague impulses, sensations and perceptions that permeate a person's whole field of awareness. Dysphoria is unfocused and not explicitly intentional; it does not possess directedness and aboutness. It is felt as unmotivated, rather indefinite and indeterminate, and often inarticulate. Dysphoria in borderline personality people exerts a centrifugal force that fragments their representations of themselves and others, thus contributing to their painful experience of incoherence and inner emptiness, their threatening feeling of uncertainty and inauthenticity in interpersonal relationships, and their excruciating sense of insignificance, futility, and the inanity of life. In the befuddled atmosphere of their dysphoric mood, borderline persons often experience their own self as dim and fuzzy, and feel deprived of a defined identity and unable to steadily be involved in a given life project or social role. Dysphoric mood brings about a formless and immaterial sense of one's own self.

Also, people affected by dysphoric mood may see others as cloudy, and their faces as expressionless. The other is an 'expressionless face(s) staring blankly at my pain' - as playwright Sarah Kane wrote. In the penumbra of dysphoria, the other may appear as the 'shade of a shadow' - it is Aeschylus speaking here. To use the words spoken by the patients themselves, the other is experienced as indefinite, indeterminate, indistinct, ill-defined, out of focus. The following is a clinical example of that: A patient enters my consultation room. When I stretch out my hand in her direction she lays her inanimate hand in mine and watches me in an interrogative way. During the therapy session she sits restlessly, remains silent and answers my questions in a provocative way. During one of the following sessions she will explain that she needed to test my interest in her, if I really cared about her, and my intention and capacity to understand her in her moody days.

The indefiniteness of the other is the norm in dysphoria. When the dysphoric mood turns into anger - as is the case in people affected by severe personality disorders like borderline personality disorder - the other changes from being opaque to being tenebrous: he is ambivalent, obscure, puzzling and suspect. During another session, the same patient looks at me right in my eyes in an angry way. She sits in a state of tension, as if she were on the point of attacking me. She remains silent for the whole session and at the end she accuses me to be her problem, and to be responsible voluntarily for her feeling so bad. What is relevant here is that when dysphoric moods fade away (and with them, the indeterminate representation of the other), anger brings about a clearcut representation of the other as a persecutor.

People affected by borderline personality disorder have biases in mental state attribution (emotions, thoughts and intentions), ${ }^{[9]}$ and may evaluate others as malevolent. Impaired social cognition or deficits in 'mentalisation' are hypothesised to underlie disturbed relatedness, a core feature of borderline personality disorder. ${ }^{[10]}$ We may argue that disturbed relatedness, through impaired social cognition, is the outcome of dysphoric mood. ${ }^{[11,12]}$ In other terms, dysphoria sets a person in a kind of life-world dominated by cognitive indecision and lack of grasp on the meaning of things and on the intentions of the others - as it is indeed the case with our patient.

In this kind of world, the principal 'pragmatic motive' is to achieve a more distinct experience and representation of the world and of other people. Manipulation, as the attempt to establish contact with others and explore their behaviour, may serve this purpose. 


\section{Empathising with manipulation}

I described manipulation as an antipathetic behaviour. Indeed, we are not keen to feel sympathy for people who manipulate others and this is an obstacle to empathising with them and to engage in understanding the motivations of their behaviour. Rather, we are tempted to stigmatise their behaviour.

The most basic form of empathy does not require any voluntary and explicit effort. We may call this type of empathy, ${ }^{[13]}$ which is at play from the very beginning of our life, non-conative - a kind of spontaneous and pre-reflective attunement between embodied selves through which we implicitly make sense of the other's behaviour. ${ }^{[1,15]}$ Sometimes, the other's behaviour becomes elusive, and we do not immediately grasp the reasons and meaning of the other's actions. While attempting to transpose myself into the other, I experience the otherness of the other. If I remain in the natural attitude, I am tempted to stigmatise the other's behaviour, which means to experience negative feelings like repulsion and aversion and to judge it 'meaningless' and 'illogical' - as is the case with our clinical example.

In order to empathise with these persons, and to make sense of their behaviour, I need to acknowledge the existential difference, the particular autonomy, which separates me from the way of being in the world that characterises each of them. Any forgetting of this difference - for instance between my own world and that of a person who 'manipulates' the others - will be an obstacle to empathic understanding, since these people live in a life-world of which the structure is (at least in part) different from my own. Achieving second-order empathy thus requires me to set aside my own prereflexive, natural attitude (in which my first-order empathic capacities are rooted) and to approach the other's world as I would do while exploring an unknown and alien country. ${ }^{[4,6-8,16]}$

\section{Conclusions}

In addition to severe aberrations of experience such as those that can be encountered in schizophrenia, also apparently more common phenomena like manipulation would seem to require a rather sophisticated and counter-intuitive kind of empathy and understanding. To achieve this kind of understanding requires a kind of training that goes beyond spontaneous (non-conative) empathic skills, as well as standard conative empathy and common-sense categories. We named this 'second-order' empathy. As shown in the case study, first of all I need to acknowledge that the life-world of the other person is not like my own, and neutralise my natural attitude that makes me approach the other's experience as if it took place in a world like our own. In the case of our patient, if we did not abandon the preconception that her manipulative behaviour had the meaning that such comportment first and foremost may have in our own life-world, then we would have simply deemed this behaviour as inappropriate and irritating. If we considered it at face value, then we would characterise it as behaviour aimed at surreptitiously producing a belief in, or action by the other.

But, if we try to reconstruct the existential structures of the world that the other lives in, then his/her behaviour may emerge as meaningful and appropriate to the pragmatic motive that dominates his/her existence - the epistemic motive to achieve a more defined representation of the other. In this way, we can then finally attempt to understand the other's behaviour in the light of his/her style of experience - in this case, the experience of the other as dim and out of focus - and, as such, as meaningfully situated in a world that is indelibly marked by the person's particular existence.

The case study of manipulation confirms that the supposition that the other lives in a world just like my own is often the cause of serious misunderstandings - the source of negative emotions and of misleading value judgments and stigmatisation that grossly interfere with one's capacity to care for other persons and to make sense of their behaviour.

\section{References}

1. Potter N. Mapping the Edges and the In-Between. A Critical Analysis of Borderline Personality Disorder. Oxford: Oxford University Press, 2009.

2. Potter N. What is manipulation behaviour, anyway? J Pers Disord 2006;20(2):139-156

3. Schutz A, Luckmann T. The Structures of the Life-World, Volume 1. Evanston: Northwestern University Press, 1973.

4. Stanghellini G. Dysphoria, vulnerability and identity. An eulogy for anger. Psychopathology 2000;33:198-203

5. McEwan I. The Child in Time. New York: Penguin, 1987.

6. Stanghellini G, Rosfort R. Emotions and Personhood. Exploring Fragility, Making Sense of Vulnerability. Oxford: Oxford University Press, 2013.

7. Stanghellini G, Rosfort R. Borderline depression: A desperate vitality. Journal of Consciousness Studies 2013;20(7-8):153-177.

8. Stanghellini G. The doublets of anger. Psychopathology 2000;33:155-158.

9. Preißler S, Dziobek I, Ritter K, Heekeren HR, Roepke S. Social cognition in borderline personality disorder: Evidence for disturbed recognition of the emotions, thoughts, and intentions of others. Frontiers in Behavioral Neuroscience 2010;4:182. [http://dx.doi. org/10.3389/fnbeh.2010.00182]

10. Roepke S, Vater A, Preißler S, Heekeren HR, Dziobek I. Social cognition in borderline personality disorder. Frontiers in Neuroscience 2013;6:195.

11. Stanghellini G. Philosophical esources for the psychiatric interview. In: Fulford KWM, ed. Oxford Handbook of Philosophy and Psychiatry. Oxford: Oxford University Press, 2013:321358

12. Stanghellini G. The ethics of incomprehensibility. In: Stanghellini G, Fuchs T, eds. One Century of Karl Jaspers' General Psychopathology. Oxford: Oxford University Press, 2013:166184 .

13. Stanghellini G. The grammar of psychiatric interview: A plea for the second person mode of understanding. Psychopathology 2007;40:69-74

14. Rochat P. Others in Mind: Social Origins of Self-consciousness. Cambridge: Cambridge University Press, 2009

15. Stern DN. The Interpersonal World of the Infant: A View from Psychoanalysis and Developmental Psychology. New York: Basic Books, 2000.

16. Stanghellini G, Rosfort R. Empathy as a sense of autonomy. Psychopathology 2013;46:337-344 